\title{
Determination of Suitability of Deoiled Cakes of Neem and Jatropha for Mass Multiplication of Pseudomonas fluorescens
}

\author{
Ajay Tomer*, Ramji Singh and Manoj Maurya \\ Department of Plant Pathology, Sardar Vallabhbhi Patel University of Agriculture \& Technology, Meerut (UP), India
}

\begin{abstract}
Jatropha cake was found to be best substrate for supporting the highest population dynamics and longevity of $P$. flourescens in vitro. Both these cakes supported the population of $P$. flourescens up to 120 days at $28 \pm 2^{\circ} \mathrm{C}$. Highest population of $P$. flourescens was noticed on jatrofa cake after 45 days of inoculation and incubation at 28 $\pm 2^{\circ} \mathrm{C}$ when maintained with $15 \%$ moisture, while on neem cake, highest population of $P$. flourescens was noticed after 60 days of inoculation when maintained with $25 \%$ moisture. Jatropha cake was better than neem cake for supporting population and longer shelf life of $P$. flourescens in vitro. Result of this study may help for using deoiled cakes of different TBOs (tree born oil seeds) in mass multiplication of different bio agent's especially $P$. flourescens.
\end{abstract}

Keywords: Longevity; Survival; Deoiled cakes; Neem; Jatropha; Cfus; Pseudomonas flourescens

\section{Introduction}

Various factors act as impediments which are known to affect the commercialization of microbial bio-control agent such as Pseudomonas fluorescens (an essential step for improving efficiency of bio-control agents). One of these impediments is the lack of technology for costeffective mass production of bio-control agents (BCAs) and their insufficient longevity during storage and transportation with a sufficient level of effective population (cfus). It is being noticed that Pseudomonas fluorescens are often effective in the laboratory, but the level of disease control, achieved in the field is sometimes disappointing and unpredictable. Some of these failures can be attributed to inadequate establishment and survival of this microorganism in soil [1]. Since they are well adapted in soil, that's why $P$. fluorescens strains are being investigated extensively for use in bio-control of plant pathogens in agriculture [2]. It is known to enhance plant growth along with yield enhancement and to reduce severity of many diseases [3].

Many agro-industrial byproducts such as deoiled cakes of tree born oils seeds (TBOs) like Neem and Jatropha which are either going waste or being used as a less profitable and less usable products since quite long time. Deoiled cakes of these trees, either remain unexploited or poorly exploited, generally as low value soil amendments or organic manure. These deoiled cakes contains good amount of N, P, $\mathrm{K}, \mathrm{Ca}, \mathrm{Mg}, \mathrm{S}, \mathrm{Fe}, \mathrm{Mn}, \mathrm{Zn}$ and $\mathrm{Cu}[4]$. In addition they also contain carbohydrates, proteins, fatty acids, and many more biochemical constituents. With these qualities, these deoiled cakes may be exploited as substrate for mass multiplication of bacterial bio-control agents such as Pseudomonas flourescens. Mass multiplication of Pseudomonas fluorescens will not only leads to value added products development from deoiled cakes of Neem and Jatropha; rather it will prevent huge wastage and inappropriate use of these by-products.

The mass cultures made at industrial scale are generally talc based, with no nutritional background to support the life of BCAs during storage, transportation and other stress. Deoiled cakes of TBOs may serve as source of diversified nutrition for BCAs when used as substrate for mass multiplication of antagonists.

\section{Materials and Methods}

\section{Sources and maintenance of culture}

Pseudomonas fluorescens culture was isolated from tomato rhizospheric soil, collected from crop research centre (CRC) of SVPUAT Meerut. For isolation of microorganism, Ten gm of soil sample adhered to roots and rootlets of tomato were collected and placed in $250 \mathrm{ml}$ conical flasks containing $100 \mathrm{ml}$ of sterilized distilled water (SDW) and mixed thoroughly. Different dilutions of working samples were prepared by serially diluting the stock solution upto $10^{-8}$. One $\mathrm{ml}$ of last serial dilution i.e., $10^{-8}$ was spread on Pseudomonas fluorescens selective king's B Medium [5] for isolation of Pseudomonas fluorescens. The plates were incubated for 2 days at $28 \pm 2^{\circ} \mathrm{C}$ and after two days of incubation, pure culture was maintained in PDA slants. Conformity of culture was done on the basis of color of bacterial colony which was initially yellow but turned yellow green as pigmentation were produced (Bonds 1957). Further culture was again reconfirmed by molecular conformity test at National Beauro of Agriculturally Important Microbes (ICAR) Mau (UP) India. The culture thus obtained was stored in refrigerator at $5^{\circ} \mathrm{C}$ for further studies and was sub cultured periodically.

Determination of population dynamics and longevity of pseudomonas fluorescens on deoiled cakes of neem and jatropha

Deoiled cakes of two tree born oilseeds i.e., Neem and Jatropha were collected from agricultural product-processing units situated in eastern Distt. Mau of Uttar Pradesh (UP) and Raipur in Chhattisgarh. Before using the cakes, they were grounded in a metallic pastel and mortar to prepare fine powder and three different level of moisture i.e., $15 \%, 25 \%$ and $35 \%(\mathrm{w} / \mathrm{v})$ were maintained by adding sufficient amount of sterilized distilled water. Before inoculation of Pseudomonas fluorescens, cakes containing different level of moisture were placed in

${ }^{*}$ Corresponding author: Ajay Tomer, Department of Plant Pathology, Sardar Vallabhbhi Patel University of Agriculture \& Technology, Meerut- 250110 (UP), India, Tel: +07830989790; E-mail: ajaytomer1489@gmail.com

Received: September 04, 2014; Accepted September 25, 2014; Published September 27, 2014

Citation: Tomer A, Singh R, Maurya M (2014) Determination of Suitability of Deoiled Cakes of Neem and Jatropha for Mass Multiplication of Pseudomonas fluorescens. J Plant Pathol Microb 5: 237. doi:10.4172/2157-7471.1000237

Copyright: (C) 2014 Tomer A, et al. This is an open-access article distributed under the terms of the Creative Commons Attribution License, which permits unrestricted use, distribution, and reproduction in any medium, provided the original author and source are credited. 
Citation: Tomer A, Singh R, Maurya M (2014) Determination of Suitability of Deoiled Cakes of Neem and Jatropha for Mass Multiplication of Pseudomonas fluorescens. J Plant Pathol Microb 5: 237. doi:10.4172/2157-7471.1000237

\begin{tabular}{|c|c|c|c|c|c|c|c|c|}
\hline Moisture level & 15 Days & 30 Days & 45 Days & 60 Days & 75 Days & 90 Days & 105 Days & 120 Days \\
\hline $15 \%$ & 122.00 & 157.33 & 187.00 & 203.00 & 183.67 & 125.00 & 84.67 & 54.33 \\
\hline $25 \%$ & 129.33 & 162.00 & 192.00 & 208.00 & 157.67 & 132.7 & 48.00 & 9.33 \\
\hline $35 \%$ & 139.00 & 168.00 & 196.67 & 176.67 & 130.07 & 98.00 & 48.00 & 10.33 \\
\hline
\end{tabular}

CD @ $5 \%$ Moisture $\%=7.0655$

Days $=11.5378$

$\mathrm{MxD}=19.984$

Table 1: CFUs of Pseudomonas fluorescens at different moisture level on sterilized Neem cake.

\begin{tabular}{|c|c|c|c|c|c|c|c|c|}
\hline Moisture level & 15 Days & 30 Days & 45 Days & $\mathbf{6 0}$ Days & $\mathbf{7 5}$ Days & $\mathbf{9 0}$ Days & $\mathbf{1 0 5}$ Days & $\mathbf{1 2 0}$ Days \\
\hline $15 \%$ & 127.33 & 188.00 & 271.00 & 211.3 & 141.33 & 97.67 & 52.00 & 16.67 \\
\hline $25 \%$ & 140.00 & 212.33 & 262.67 & 197.00 & 131.00 & 92.00 & 43.00 \\
\hline $35 \%$ & 148.00 & 236.67 & 254.00 & 214.00 & 171.00 & 103.00 & 46.67 & 17.67 \\
\hline
\end{tabular}

C.D@ moisture $\%=1.2504$

Days $=2.0419$

$\mathrm{MxD}=3.537$

Table 2: CFUs of Pseudomonas fluorescens at different moisture level on sterilized Jatropha cake.

$250 \mathrm{ml}$ capacity conical flasks (@75 gram/flask), plugged tightly with cotton plugs, wrapped with butter paper and autoclaved at $121.6^{\circ} \mathrm{C}(1.1$ $\mathrm{kg} / \mathrm{cm}^{2}$ ) for 20 minutes. After inoculation, flasks were allowed to cool overnight at room temperature prior to inoculation. Flasks containing sterilized deoiled cakes with different level of moisture were inoculated with 3-4 days old actively growing culture of Pseudomonas fluorescens (2-3 bits of $5 \mathrm{~mm}$ size from the culture grown on PDA in Petri plates) under aseptic conditions in laminar flow. For each moisture level and each set of duration (Tables 1 and 2) three replicates were maintained. Flasks inoculated with Pseudomonas fluorescens were incubated at $28 \pm$ $2{ }^{\circ} \mathrm{C}$ in a BOD incubator and shaken thoroughly once a day to provide sufficient substrate to grow properly.

\section{Monitoring of population dynamics in deoiled cakes}

Population of Pseudomonas fluorescens was monitored from the deoiled cakes of Jatrofa and Neem maintained with different level of moisture (15\%, 25\% and 35\% respectively) after each 15 days interval upto 120 days. For this purpose, $1 \mathrm{gm}$ of each cakes where Pseudomonas flourescens was inoculated was taken from each flasks maintained for different duration i.e., 15 to 120 days and CFUs were counted using PDA through dilution plate technique/Simplified agar plate method for quantifying viable bacteria [6].

\section{Results}

\section{Screening of deoiled cakes of Neem and Jatropha for mass multiplication of Pseudomonas fluorescens}

Deoiled cakes of two Tree Born Oilseeds (TBOs) i.e., Neem and Jatropha Were tested for their suitability to support the population dynamics and longevity of Pseudomonas fluorescens at three different level of moisture i.e 15\%, 25\% and 35\%. Results obtained have been presented in (Tables 1 and 2).

\section{Neem cakes}

Neem cake with $35 \%$ moisture resulted in $139.00 \times 10^{8}$ number of CFUs of Pseudomonas fluorescens at 15 days of inoculation. At 30 days of inoculation neem cake with $35 \%$ moisture resulted in $168.00 \times 10^{8}$ CFUs of $P$.fluorescens, whereas at 45 days of inoculation the population of $P$.fluorescens increased to $196.67 \times 10^{8}$ and at 60 days of inoculation, it further goes down to the level of $176.67 \times 10^{8}$. At 75 days of inoculation Neem cake with 35\% moisture showed further reduction in the Pseudomonas population and accordingly CFUs decreased to $137.00 \times 10^{8}$. At 90 days of inoculation, the Neem cake with
$35 \%$ moisture resulted in $98.00 \times 10^{8}$ number of CFUs of $P$.fluorescens. At 105 days the number of CFUs of $P$.fluorescens, recovered from the cakes were $48.00 \times 10^{8}$, whereas at 120 days, the CFUs of $P$. Fluorescens recovered, were $10.33 \times 10^{8}$. In the case of neem cake the population of $P$. Fluorescens observed at each 15 days interval differed significantly from each other while different level of moisture hardly had significant effect on the increase or decrease of population.

\section{Jatropha cake}

Jatropha cake containing $35 \%$ moisture resulted in $148.00 \times 10^{8}$ level of CFUs of Pseudomonas fluorescens at 15 days of inoculation. At 30 days of inoculation, the number of CFUs increased to the level of $236.67 \times 10^{8}$, whereas at 45 days the population further increased to the level of $254.00 \times 10^{8}$ CFUs of Pseudomonas fluorescens. At 60 days onward there was declining trend and population declined to the level of $214.00 \times 10^{8}$ and at 75 days it was $171.00 \times 10^{8}$. At 90 days of inoculation the Jatropha cake containing 35\% moisture, resulted in $103.00 \times 10^{8}$ level of population of $P$.fluorescens. At 105 days the $P$ fluorescens population decreased to the level of $46.67 \times 10^{8}$ and at 120 days population further declined to the level of $17.67 \times 10^{8}$. Level of CFUs recorded after each 15 days interval and each level of moisture were significantly different from each other.

In the comparison of two deoiled cakes it was found that jatropha cake was quite superior over neem cakes in supporting the population dynamics of Pseudomonas fluorescens. In case of neem cake, increasing the level of moisture didn't have any significant effect on population dynamics of Pseudomonas fluorescens, whereas in case of jatropha cakes, with increasing in the level of moisture had resulted in significant increase of population dynamics of Pseudomonas fluorescens.

\section{Discussion}

\section{Cakes of neem and jatropha}

With a purpose to find out a suitable substrate for mass multiplication and also for a longer shelf life of Pseudomonas fluorescens, an experiment was conducted to test the suitability of two de-oiled cakes of Neem and Jatropha with three moisture level i.e. $15 \%, 25 \%$ and $35 \%$. Results indicated that Jatropha cake was found to be comparatively better than neem cake for enhancing population of Pseudomonas fluorescens with a highest level after 45 days of inoculation with $15 \%$ moisture. It was also noticed that Jatropha and neem cake both could support the population and longevity upto 120 days with $\times 10^{8}$ level of population. In case of neem cake it was observed 
that on neem cake population of Pseudomonas fluorescens was found to be increasing upto 60 days after inoculation with a highest at 60 days after inoculation with $25 \%$ moisture, while on Jatropha cake population of Pseudomonas fluorescens was found to be increasing upto 45 days only and after that there was a trend of decline in the population of Pseudomonas fluorescens. In case of neem cake upto 60 days increase in the moisture level resulted with increase of population but after 60 days onward increase in the moisture resulted in decrease of population. In case of Jatropha cake upto 45 days only increase in the moisture level resulted with increase in population but after 45 days onward increase in the moisture resulted in decrease in population of Pseudomonas fluorescens.

Reason behind higher population dynamics of Pseudomonas fluorescens on the de-oiled cakes of two tree born oilseeds (TBO's) may be because of their richness and sufficiency of different type of nutrients, minerals and other constituents which are required and may be supportive for multiplication of Pseudomonas fluorescens . Reason behind decline of population dynamics after 45/60 days during present investigation may be that, at the initial level there may be plenty of nutrition available to be utilized for multiplication of Pseudomonas fluorescens which later get declined, because they might have been exhausted day by day due to utilization and exploitation by growing Pseudomonas fluorescens in the substrate itself and resulted in poor supply after $45 / 60$ days and thereby lower population dynamics with prolonging duration of storage.

Nilkamal et al. [7] assessed Deoiled Jatropha cake as substrate for enzyme production by solid-state fermentation (SSF). Solvent tolerant Pseudomonas aeruginosa PseA strain was used for fermentation. The seed cake supported good bacterial growth and enzyme production (protease, $1818 \mu \mathrm{g} / \mathrm{g}$ of substrate and lipase, $625 \mu \mathrm{g}$ /g of substrate). Maximum protease and lipase production was observed at $50 \%$ substrate moisture, at a period of 72 and $120 \mathrm{~h}, \mathrm{pH}$ of 6.0 and 7.0, respectively. Murugalakshmi et al. [8] reported that Agricultural residues rich in carbohydrates can be utilized in fermentation process to produce microbial protein which in turn can be used to determine the factors influencing cell biomass production. Pseudomonas fluorescens was cultivated using banana peel out, watermelon skin, and Cane molasses showed that the strain was capable of meeting its components required for growth. The organism was capable of growth at $28^{\circ} \mathrm{C}$, when supplemented with agricultural wastes in different concentration mixed with agar. The number of colony forming units was more when compared with nutrient agar. Abhinav et al. [9] evaluated PGPR strain of Pseudomonas fluorescens PS1 to formulate carrier based bioformulations. The viability of Pseudomonas fluorescens PS1 was monitored at different time intervals during the period of storage at room temperature in different carriers such as soil, charcoal, sawdust and sawdust-soil. Sawdust-soil was found to be the most efficient carrier material for P. fluorescens PS1 followed by other carriers. Sangeetha et al. [10] studied the survival of PGPR isolates by using different carrier materials. The carrier based PGPR consortium with four selected strains viz., Azospirillum lipoferum VAZS-18, Azotobacter chroococcum VAZB-6, Bacillus megaterium VBA-2, Pseudomonas fluorescens VPS-19 was prepared and the shelf life for each inoculants was studied upto six months of storage. The surviving population in the lignite based consortium was $1.64 \times 10 \mathrm{cfu} \mathrm{g}^{-1}$ for Azospirillum lipoferum VAZS-18, $1.46 \times 10 \mathrm{cfu} \mathrm{g}$ for Azotobacter chrococcum, VAZB-6, $1.22 \times 10 \mathrm{cfu} g$ for Bacillus megaterium VBA-2 and $2.01 \times 10 \mathrm{cfu} g$ for Pseudomonas fluorescens VPS-19 after six month of storage. The surviving population in vermiculite based consortium was $4.32 \times 10 \mathrm{cfu}$ $\mathrm{g}$ for Azospirillum lipoferum VAZS-18, $1.98 \times 10^{-1} \mathrm{cfu} g$ for Azotobacter chroococcum $\mathrm{V}_{8} \mathrm{AZB}-6,1.14 \times 10^{8} \mathrm{cfu}^{-1}$ for Bacillus megaterium VBA2 and $3.32 \times 10 \mathrm{cfu} g$ for Pseudomonas fluorescens VPS-19 after six months of storage. In the pressmud based consortium, the surviving population was $3.25 \times 10 \mathrm{cfu} g$ for Azospirillum lipoferum VAZS-18, $3.00 \times 10^{8} \mathrm{cfu} g$ for Azotobacter chroococcum VAZB-6, $2.14 \times 10^{-1} \mathrm{cfu} g$ for Bacillus megaterium VBA-2 and $3.42 \times 10 \mathrm{cfu} \mathrm{g}^{-1}$ for Pseudomonas fluorescens VPS-19 after six months of storage. In the alginate bead based consortium the surviving population was $64.61 \times 10 \mathrm{cfu} \mathrm{g}$ for Azospirillum lipoferum VAZS-18, $56.81 \times 10 \mathrm{cfu} g$ for Azotobacter chroococcum VAZB-6, $47.83 \times 10$ cfu g for Bacillus megaterium VBA2 and $63.89 \times 10^{8} \mathrm{cfu} \mathrm{g}^{-1}$ for Pseudomonas fluorescens VPS-19 after six months of storage. Although scanty literatures are available regarding use of deoiled cakes for mass multiplication of Pseudomonas fluorescens but after thorough scanning of literature it is clear that the carriers rich in organic substances and carbohydrate are highly supportive of multiplication of Pseudomonas fluorescens thus the findings of present studies are well supported by previous findings as mentioned above [11].

Based on the findings reported by all the groups mentioned above it is clear that the material rich in either protein or carbohydrates have been found to be comparatively better carrier for mass multiplication of Pseudomonas fluorescens as compared to those substrates which or either nutrient less like agar based or having less nutrient. Thus the findings of these workers are in conformity with the present findings [12]

\section{Conclusion}

De-oiled cakes of two trees born oilseeds (TBOs) viz., Neem and Jatropha were tested as solid substrate for their suitability for mass multiplication of Pseudomonas flourescens Among two deoiled cakes, Jatropha cake was found to be best substrate in supporting the population dynamics and longevity as well of Pseudomonas flourescens in vitro. Neem cake was next in order to support the population of Pseudomonas flourescens rather closely followed the Jatropha cake in supporting the population and longevity of Pseudomonas flourescens in vitro.

Both these cakes (Neem and Jatropha) supported the population of Pseudomonas flourescens up to 120 days with a considerable level of viable counts of Pseudomonas flourescens.

Highest population of Pseudomonas flourescens was noticed on jatrofa cake after 45 days of inoculation when maintained with $15 \%$ moisture, while on neem cake highest population of Pseudomonas flourescens was noticed after 60 days of inoculation when maintained with $25 \%$ moisture. Jatropha cake was better than neem cake for supporting population and longer shelf life of Pseudomonas flourescens in-vitro.

Jatropha cake helped to increase the population of Pseudomonas flourescens up to 45 days and thereafter it was decreased, whereas neem cake helped to increase the population of Pseudomonas flourescens up to 60 days and thereafter it was decreased.

Increasing the moisture level resulted in enhancement of total viable count of Pseudomonas flourescens on both deoiled cakes i.e. neem cake and Jatropha cake. After duration of 120 days also the viable counts of Pseudomonas flourescens were $\times 10^{8}$.

Both these cakes supported the population of Pseudomonas flourescens up to duration of 120 days with a considerable level of viable counts of Pseudomonas flourescens. Based on the findings of present 
Citation: Tomer A, Singh R, Maurya M (2014) Determination of Suitability of Deoiled Cakes of Neem and Jatropha for Mass Multiplication of Pseudomonas fluorescens. J Plant Pathol Microb 5: 237. doi:10.4172/2157-7471.1000237

studies these deoiled cakes i.e. Neem and jatropha both can be used as a carrier for mass multiplication of Pseudomonas flourescens and can be applied to crop/soil.

\section{Acknowledgments}

Help and support received from SVPUAT Meerut and NOVOD Board during the course of investigation is dully acknowledged.

\section{References}

1. Elliot LF, Lynch JM (1995) The International Workshop on the Establishment of Microbial Inocula in soils. Cooperative research project on biological resource management of the Organisation for Economic Cooperation and Development (OECD). Am J Altern Agric 10: 50-73.

2. Ganeshan G, Kumar MA (2006) Pseudomonas fluorescens a potential bacteria antagonist to control plant diseases. J Plant Interactions 3: 123-134.

3. Hoffland E, Halilinen J, Van Pelt JA (1996) Comparison of systemic resistance induced by avirulent and non-pathogenic Pseudomonas sp. Phytopathology 86: 757-762

4. Patolia (2007) Preparing Status Reports on Themes Related to Technical and Scientific Aspects of Biofuels Utilization by Winrock International India (WII) New Delhi India

5. King EO, Ward MK, Raney DE (1954) two simple media for the demonstration of Pyocyanin and fluorescin. Journal of Laboratory and Clinical Medicine 36: 100-102.
6. Jett BD, Hatter KL, Huycke MM, Gilmore MS (1997) Simplified agar plate method for quantifying viable bacteria. Biotechniques 23: 648-650.

7. Neelkamal M, Gaur R, Gupta A, Khare SK (2008) Purification and characterization of lipase from solvent tolerant Pseudomonas aeruginosa PseA. Biological Sciences 43: 1040-1046.

8. Murugalakshmi CN, Sudha SS (2010) The Efficacy of agro waste on cultivation of Pseudomonas fluorescens. A potential biocontrol agent International Journal of Biological Technology 1: 32-34.

9. Abhinav A, Dubey RC, Maheshwari D K, Pandey P, Bajpai K, et al. (2011) PGPR strain Pseudomonas fluorescens PS1 was evaluated to formulate carrier based bioformulations. European Journal of Plant Pathology I: 81-93.

10. Sangeetha D (2012) Survival of plant growth promoting bacterial inoculants in different carrier materials. International Journal of Pharmaceutical \& Biological Archive 3: 221-243.

11. Ambardar VK, Sood AK (2010) Suitability of different growth substrate for mass multiplication of bacterial antagonists. Indian Phytopathology 63: pp.4

12. Bonde GJ, Jensen CE, Thamsen J (1957) Studies on a water soluble fluoresceing bacterial pigment which depolymerizes hyaluronic acid. Acta Pharmacol Toxicol (Copenh) 13: 184-193. 